\title{
J. C. Quick and L. E. Tetrick (eds): Handbook of Occupational Health Psychology, 2nd ed
}

\author{
American Psychological Association, Washington, DC, 2011, \\ $441 \mathrm{pp}, \$ 63.80$ (hardbound)
}

\author{
Bruce A. Barron
}

Published online: 21 August 2011

(C) Springer Science+Business Media, LLC 2011

\begin{abstract}
A large volume of research and literature has been written about employee health during the past several decades. A preponderance of occupational health publications have focused on the primary, secondary, and tertiary prevention of work-related musculoskeletal, neurologic, dermatologic, and pulmonary disorders. Although important in terms of employee health and productivity, relatively little information has been published on the psychological aspects of employee and organizational health. The specialized field of occupational health psychology develops, maintains, and promotes the health of employees through the prevention of injury and illness [1]. These factors made the publication of the 2nd edition of the Handbook of Occupational Health Psychology (Handbook) both timely and necessary.
\end{abstract}

The Handbook was edited and written by eminent experts in the field of occupational health psychology. Part I of the book reviewed the mission and history of occupational health psychology, important chapters for those readers unfamiliar with this discipline. Part II discussed various models and frameworks for occupational stress, savoring eustress, controlling occupational health and safety hazards, organizational wellness, and cross-cultural occupational health psychology. Part III reviewed causes and risks such as corporate safety climate, work-family life balance, and work schedules. Part IV was particularly interesting in that it discussed symptoms and disorders such as job-related burn-out, cardiovascular disease, and substance abuse from the unique perspective of an occupational health psychologist. Interventions and treatments for disorders associated with psychological etiologies were subsequently examined in Part V. The last second, Part VI, summarized research designs and a strategy to evaluate occupational health psychology programs.

The Handbook is unquestionably an authoritative, stateof-the-art resource on occupational health psychology. It is chock full of references and is evidence-based. Overall, the book reads like a refereed review article, offering much in the way of information, but little in terms of practical application in real-world settings. Despite this shortcoming, the Handbook would be an excellent resource for researchers, scholars, students, and practitioners in occupational health psychology, in addition to occupational health specialists in other disciplines, disability case managers, and policymakers.

\section{Reference}

1. Quick JC, Tetrick LE. Handbook of occupational health psychology. 2nd ed. Washington, D.C.: American Psychological Association; 2011:4.

\footnotetext{
B. A. Barron $(\square)$

Division of Occupational and Environmental Medicine, University of Rochester School of Medicine and Dentistry, Rochester, NY, USA

e-mail: bruce_barron@urmc.rochester.edu
} 